\title{
FLOOD MONITORING SYSTEM USING THINGSPEAK WEB SERVER AND IFTTT
}

\author{
K. Sundar Srinivas \\ Asst. Professor \\ Department Of Electronics And Communication Engineering \\ Potti Sriramulu Chalavadi Mallikarjuna Rao College Of Engineering \& Technology, \\ Vijayawada \\ Sajid Baig, T. Navya Sri, Y. Praneeth, V. Naga Lakshmi \\ Student \\ Department Of Electronics And Communication Engineering \\ Potti Sriramulu Chalavadi Mallikarjuna Rao College Of Engineering \& Technology, \\ Vijayawada
}

\begin{abstract}
Flood monitoring system is a system that is developed using the platform of ThingSpeak web server to get $t$ stored or retrivedwhich is of data from the systems using the protocal of HTTP in LAN. This system relies on two NodeMCU boards in which one act as transmitter and another as receiver the ThingSpeak application acts as server. Two NodeMCU's are placed at the flood proned areas in which one NodeMCUwill be acting as transmitting unit in which it consists of a Water level sensor that is used for the detecting the level of water and this data is sent to ThingSpeak server to get stored. In order to find the rate of flow, temperature, humidity and level, a water flow, level and DHT11 sensors were used, they send the values to ThingSpeak application. The web server stores all the data in private channel by defaultly, but there is an option to share data to the general public by using the public channel. And second NodeMCU consists of Buzzer and LED so that if the threshold is reached the the buzzer and LED gets on. The results obtained tells that the system can be used at Flood prone areas.
\end{abstract}

\section{INTRODUCTION}

Flood is a natural disaster where an area of land that get instantly submerged in water. Flood may occur in many areas in different ways due to overflow of streams, rivers, lakes or oceans or as a result of excessive rain $\mathrm{A}$ warning system is necessary to take precautionary measures and be more prepared to overcome its effects [1].

This project aims at alerting the authorities about an imminent flood by monitoring the water level at flood proned areas which have high impact on that areas. Also the rainfall pattern of the area and the forecast for the area is considered. This information will enable the authorities to be more prepared in the eventuality of a flood [2].

Flash floods are one of the most dangerous disasters that causes the major losses in life, environment, and economics as I occurs very suddenly. Similar to events of many countries, a report suggests that loss of flash floods can be prevented by using early warning system It describes loss from flash flood in many countries and provides directions in both research and applications by four topics. One topic of those is to improve in forecasting and warning. Flash flood is a disaster that requires fast detection in order to prevent major loss of life due to it [3].

This monitoring device uses the platform of ThingSpeak web server for storage and reception of data from the systems using the protocol of HTTP over LAN. This system consists of two NodeMCU's in which one NodeMCU board is placed in the flood proned area where the NodeMCU will work as the transmitting unit which consists of an Water level sensor that is used for the detection of the level of water at the time of floods and then the data is stored in ThingSpeak web server. In order to find the flow rate a water flow meter is used which send the flow rate to the ThingSpeak web server. ThingSpeak stores data in privately in private channel by default. Thus, the result obtained shows the designed system is capable of monitoring the flood prone areas [4].

\section{LITERATURE SURVEY}

The existing real time flood monitoring system with Wireless Sensor Networks (WSN) refers to the system to develop a local flood monitoring and warning system. In the existing system the base station collects the packets from sensor node and 
then transfers them to back end server via ADSL/CDMA.

After studying the existing real time flood monitoring system with Wireless Sensor Networks. We observed that this system cannot provide or measures the different environment conditions using Wireless Sensor Networks, and also noticed that the existing WSN of flash flood alerting cannot provide forecasting of future disasters.

So in this case of floods it takes more time to send message to the people living in the nearest area so that the people could not save there lives. Usually the flood cannot be predicted but the early detection can be made it means the early alerting system with the help of continuous monitoring can be useful to reduce the loss caused by the floods.[1] To develop an advanced IOT technology monitoring system. Firstly to measure the water level, flow and to alert the surrounding people in remote areas using flood monitoring system. All the information is sent to ThingSpeak webserver, for our system we have referred some IEEE papers and we studied and come to know our proposed system is an IoT based flood monitoring system that measures the water flow rate and water level. In this system the most important one is prototype the level of water, The parameter of water tells that the flood occurrence especially in disaster prone area. If the water level reaches the threshold limit the signal will be freed in real time to social network like twitter, SMS, Gmail etc. A ThingSpeak web server was used to store the data and displayed in remote display board.[2]

\section{METHODOLOGY}

The Flood monitoring system is divided into software and hardware modules. The methodology can be discussed as following:

\section{A. BLOCK DIAGRAM}

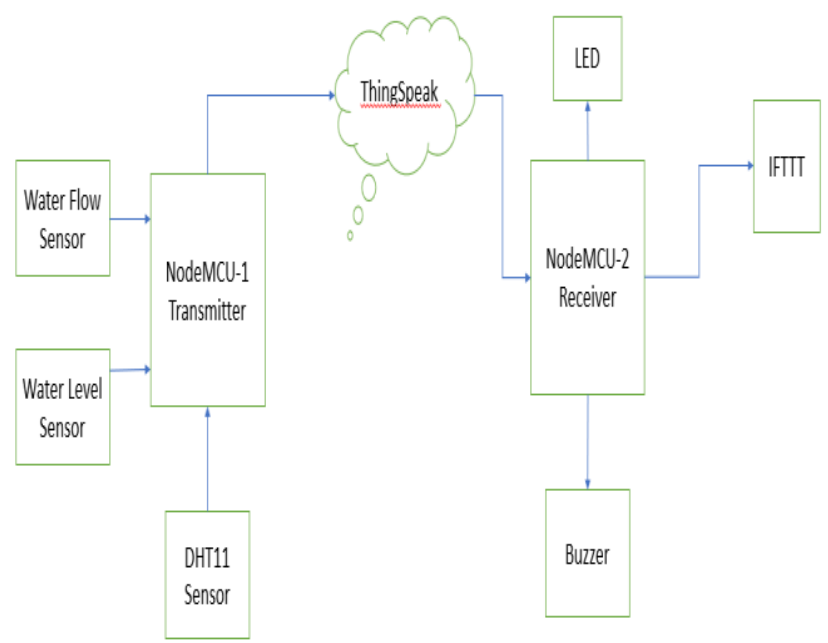

Figure 1: Block diagram of the system
Figure 1 shows the block diagram of the flood monitoring system. In this project we are using three sensors to find out three different parameters. One is water level sensor which is used to find the water level of a river, water flow sensor which is used to determine the flow rate of the river and other is DHT11 sensor to find humidity and temperature of surroundings. For sending the SMS to authorities to alert the situation during flood times we are using IFTTT web server. For monitoring the data of these three parameters we are using an external web server called ThingSpeak.

\section{B. WATER LEVEL SENSOR:}

"Level sensor is used to a detect the level of a substances that can flow. Such substances like a liquids, powders, granular material and slurries. Level measurements can be done inside containers or it can be the level of a river or lake. Such measurements can be used to determine the amount of materials within closed container or the flow of water in open channels."

Water level sensor consists of three pins; those are VCC, GND, SIGNAL pins. It requires $5 \mathrm{v}$ to operate and in this project in order to find the water level of a river we use this water level sensor. The Signal pin of water level sensor is connected to A0 pin of the NodeMCU, +ve pin of water level sensor is connected to pin of $3.3 \mathrm{~V}$ in NodeMCU and -ve pin of water level sensor is connected to GND pin of NodeMCU.Firstly, the data of NodeMCU will be sent to the ThingSpeak application. The data present in the ThingSpeak helps the authorities to take precautions. If there is change in the level of water.

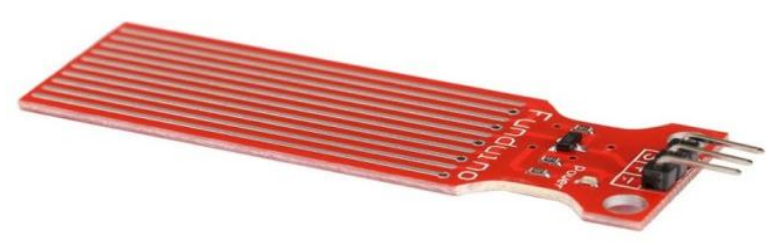

Figure 2: Water level Sensor

\section{WATER FLOW SENOR:}

Water flow sensor is used to find the flow rate and we can find the quantity of water that is flowing through river. It consists of 3 pins. VCC, GND and Data pin. It requires $5 \mathrm{~V}$ to operate. The Data pin is connected to $\mathrm{D} 2, \mathrm{VCC}$ is connected to $3.3 \mathrm{v}$ and GND to GND pins of NodeMCU. When water flows into the sensor then the force caused by the water makes the wheel which is placed inside of the sensor to rotate. The water flow rate can be 
found by calculating the number of rotations that the wheel has done.

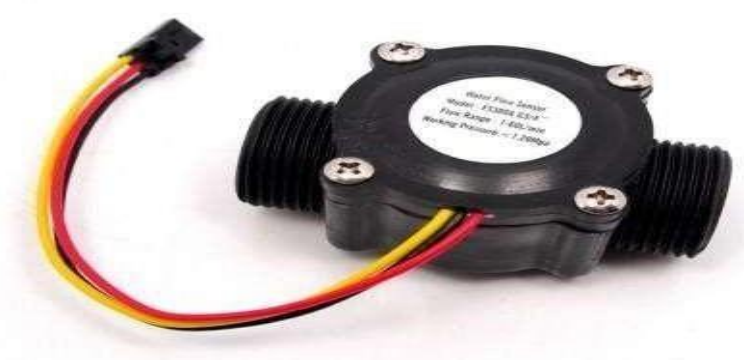

Figure 3: Water Flow Sensor

\section{DHT11 SENSOR}

DHT11 Sensor is used to detect both temperature and humidity in the surrounding environment. It consists of four pins they are Signal, VCC, GND, Not Connected. It requires $5 \mathrm{~V}$ to operate. The signal is connected to $\mathrm{D} 3$ pin, $\mathrm{VCC}$ to $3.3 \mathrm{v}$ pin and GND to GND pin of NodeMCU. "Consists of a capacitive humidity sensing element and a thermistor for sensing temperature. For measuring temperature this sensor uses a Negative Temperature coefficient thermistor", which causes a decrease in its resistance value with increase in temperature. To get larger resistance value even for the smallest change in temperature. For measuring Humidity the capacitor has two electrodes with a moisture holding substrate as a dielectric between them. Change in the capacitance value occurs with the change in humidity levels.

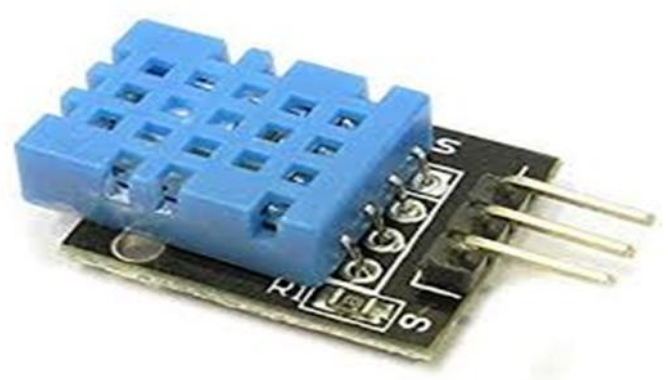

Figure 4: DHT11SENSOR

\section{E. THINGSPEAK WEB SERVER:}

ThingSpeak is an open source IoT application and API that allows you to aggregate, visualization and analyse live data streams in the could. ThingSpeak utilizes HTTP Convention to communicate. You can send data to ThingSpeak from your devices and also we can use the graphs as well as numerical display to monitor the data which is updated from sensor via internet. It also create instant visualization of live data and send alerts using web services like twitter and Twilio. The main advantage of the ThingSpeak is triggering the certain link if certain conditions are meeting.

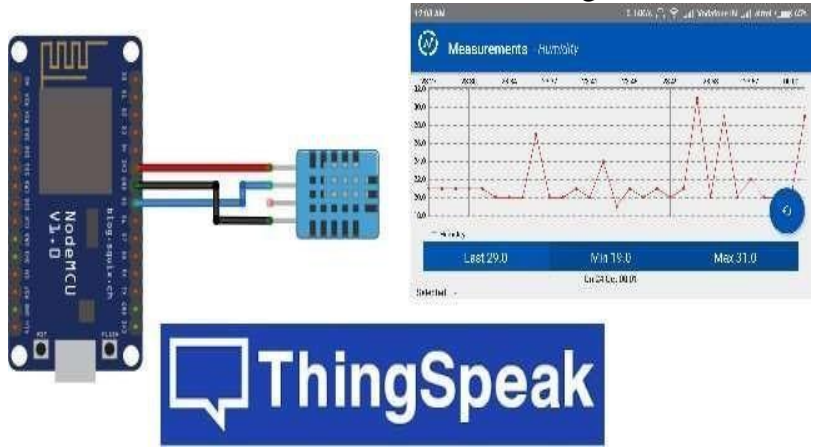

Figure 5: ThingSpeak

\section{F. IFTTT}

IFTTT stands for If This Than That. It means that if any trigger happens then the action has to be performed. It is an open source web-based service that will create chains of simple conditioned statements called applets. An applet creating procedure consists of 7 different steps and we need only one operating mobile with an active sim. After completion of 7 steps successfully we get an URL Which can be used for triggering the SMS applet. In our project we have created an applet which contains two apps, one is to store the data from sensors and other one is SMS app. This IFTTT is for not only sending SMS's but also push Gmail, Facebook notifications etc.

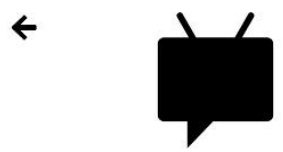

$\$$

\section{Android SMS}

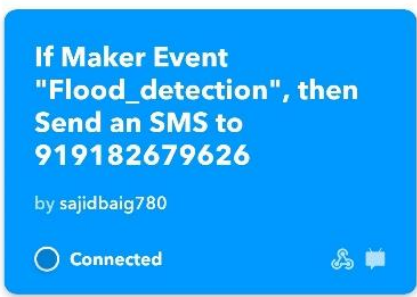

If Maker Event

"Flood detection", then

Send an SMS to

919182679626

connected

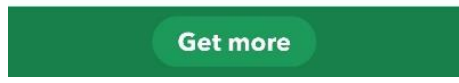

Figure 6: IFTTT SMS Applet

\section{SYSTEM ANALYSIS}

This system is used for detecting the flood and to alert the authorities by monitoring the water level and water flow of the river or dam or lake or flood prone area so that it is monitored continuously time 
to time and the flow sensor detects the flow rate of the water and update it in the web application thing speak and if the level of dam or river cross it limit then the water level sensor gets dipped in water and if the hed then a SMS alert is sent to authorities through IFTT .

\section{F. FLOW CHART}

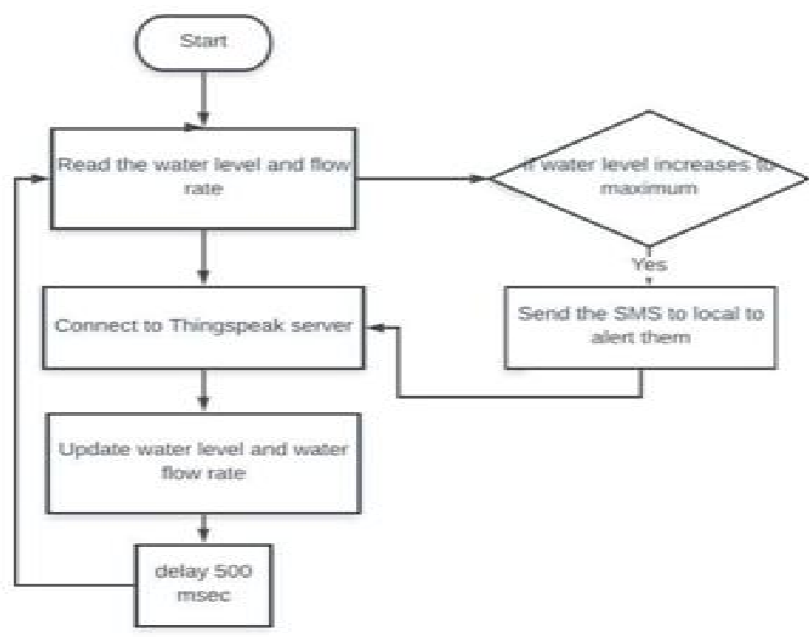

Figure 7: Flow chart

From the flow chart, the values of water level and water flow of the river are read through NODEMCU and next updated these values to ThingSpeak. The ThingSpeak will compare the updated water level with threshold and if the water level is above threshold then the ThingSpeak will automatically trigger an external website that is IFTTT. com in which our applet is there. Whenever the ThingSpeak trigger the URL, with in no time an SMS request will be send to mobile as alert message.

\section{RESULTS}

The project "FLOOD MONITORING SYSTEM USING IOT" has been successfully designed and tested. In this project, a device is built using PCB board used in flood prone areas to detect water flow, level, temperature and humidity of the area if the level reaches the threshold then it alerts the authorities. It is of low cost, and best solution to for detecting the floods. This system is shown in below figure 8 .



Figure 8: project setup.

After the completion of task an undertaking was prepared to check. The artificial connection between NodeMCU and Web Server and Web Server to IFTTT is successfully obtained. The data was updated in the fields of ThingSpeak channel and triggering is done successfully. This prototype has been tested only at one location and the result is shown below.

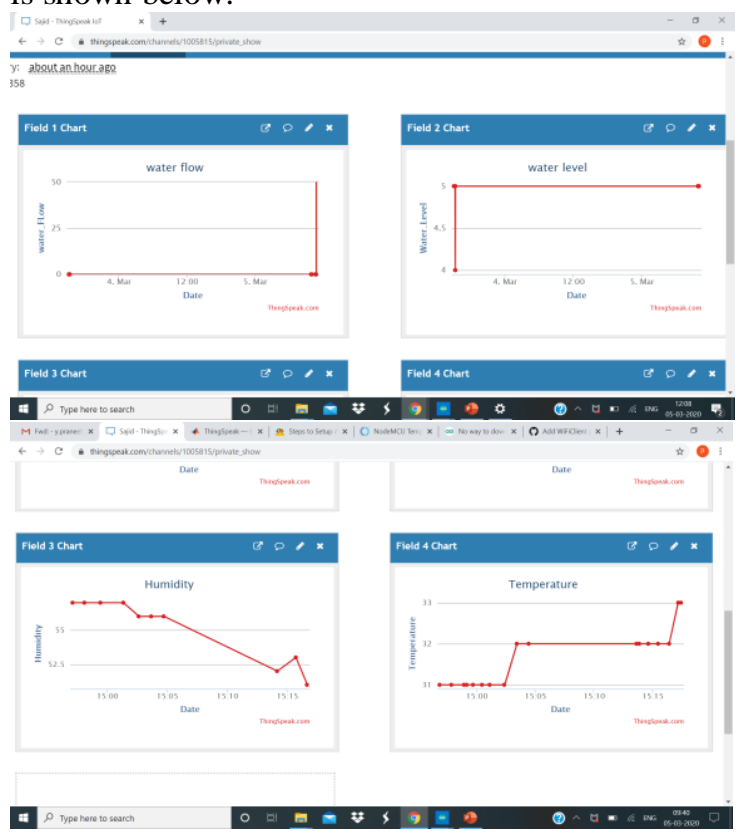

Figure 9: Results from the Thingspeak website

In the $9^{\text {th }}$ figure, we can observe four graphical displays in which $1^{\text {st }}$ one shows the water level, the second one is water flow rate in terms of Liters per hour, third one show's the temperature and the fourth one shows the humidity in the surrounding area. If the water level reaches above the fixed threshold the it sends an SMS alert using IFTTT which is shown in figure 10. 
International Journal of Engineering Applied Sciences and Technology, 2020

Vol. 5, Issue 1, ISSN No. 2455-2143, Pages 639-643

Published Online May 2020 in IJEAST (http://www.ijeast.com)

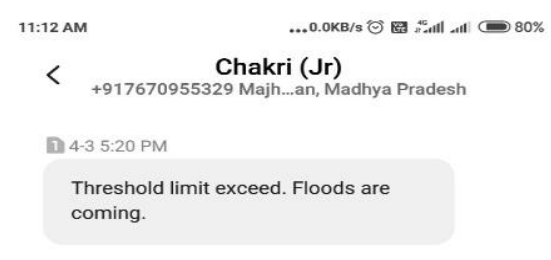

Figure 10: IFTTT applet message

\section{REFERENCES}

[1] Ar. K. Lavanya, (2012) Urban Flood Management - A Case Study of Chennai City, Architecture Research, pg-115-121.

[2] M.S. Baharum, R. A. Awang and N. H. Baba, (2011) Flood Monitoring System,IEEE International Conference on System Engineering and Technology (ICSET) .

[3] H. Hamidon, (2010) "Flood level indicator and risk warning system for remote location monitoring using flood observatory system," WSEAS Trans. Syst. Control, vol. 5, no. 3, pp. 153-163.

[4]. A.C. Khetre1, Prof.S.G. Hate2, (2013), Automatic monitoring \& Reporting of water quality by using WSN Technology and different routing methods.

[5] Chang, Y., and Chang, N(2002). "The design of a web-based decision support system for the sustainable management of an urban river system", Water Science and Technology 46(6),pp. 131-139.

[6] Qinggong Ma, Bo Yang, Jipeng Wang,(2017) "Application of Internet of Things in Urban Flooding Prevention Management System", Scientific Research Publishing,Advances in Internet of Things, 2017, 7, 1-9, ISSN Print:21616817.

[7] U.S. De, G. P. Singh and D. M. Rase,(2013) Urban flooding in recent decades in four mega cities of India, J. Ind.Geophys. Union, April 2013,Vol.17, No.2, pp. 153-165.

[8] Xue, X.G., Jiang, S.F., Li, M., et al.(2016) Application Trend of GIS in Urban Drai-nage and Flooding Prevention. Science \& Technology Vision, No. 1,pp. 71-72.
[9] Elizabeth, A. Basha, (2008)"Model-Based Monitoring for Early Warning Flood Detection" .

[10] Khalid Parveez,(2012) "A Smart Zigbee Based Wireless Weather Station Mon-itoring System", International Conference on Computing and Control Engineering (ICCCE 2012), 12 and 13 April, 2012

[11] Real time flood monitoring system, Environmental Science and Information Application Technology (ESIAT), 2010 International Conference, Publisher: IEEE, Conference Location : Wuhan, China.

[12]. S Vara Kumari, O Sailaja, N V S Rama Krishna, Ch Thrinisha, Early Flood Monitoring System using IoT Applications

[13]. Edward N. Udo1, Etebong B. Isong2, Flood Monitoring and Detection System using Wireless Sensor Network

[14]. Sheikh Azid, Bibhya Sharma, Krishna Raghuwaiya, Abinendra Chand, Sumeet Prasad, A Jacquier, Sms based flood monitoring and early warning system

[15]. Jagadeesh Babu Mallisetty and Chandrasekhar V, IOT based real time flood monitoring and alert management system 